\title{
МЕТОДИКА СКОРИНГОВОЙ ОЦЕНКИ ЭФФЕКТИВНОСТИ СТАРТАПОВ СФЕРЫ УСЛУГ
}

\author{
(c) 2019 Мухаметшина Гульназ Расимовна \\ доцент кафедры общего менеджмента Института управления, экономики и финансов \\ Казанский (Приволжский) федеральный университет, Россия, Казань \\ E-mail:698817@mail.ru
}

(c) 2019 Казанцева Регина Саитгалеевна

магистрант Института управления, экономики и финансов

Казанский (Приволжский) федеральный университет, Россия, Казань

В статье показана актуальность количественной оценки эффективности современных стартапов сферы услуг. Систематизированы основные проблемы скоринговой оценки, как одного из наиболее распространенных методов исследования эффективности стартапов. Аргументирована методика усовершенствованной скоринговой оценки эффективности стартапов. Отличительными особенностями усовершенствованной методики являются: учет в единой системе координат не только конъюнктурной, но и возможной долгосрочной эффективности стартапа; разностороннее исследование параметров стартапа (инновационность, интегративность, качество кадрового, финансового обеспечения и т.п.); оценка степени сбалансированности отдельных параметров стартапа посредством расчета среднего квадратического отклонения баллов.

Ключевые слова: стартап, сфера услуг, экономическая эффективность, скоринг, инновационность, сбалансированность.

Результативность реализации стартапов сферы услуг в современных условиях хозяйствования непосредственно зависит от точности количественной оценки уровня их потенциальной экономической эффективности. Собственно, такого рода оценка эффективности стартапов имеет существенное значение для следующих групп экономических субъектов:

- для самих инициаторов стартапа с точки зрения планирования того, следует ли в дальнейшем тратить на его осуществление и продвижение определенные временные и человеческие ресурсы;

- для потенциальных инвесторов, в части возможного принятия решения о вложении денежных средств в развитие и совершенствование стартапа;

- для возможных кредиторов стартапа;

- для органов государственной власти и управления, занимающихся развитием венчурного сегмента экономики, которые в зависимости от оценки потенциальной эффективности могут принимать решение о целесообразности, формах и объемах осуществления бюджетной поддержки отдельных стартапов.

Вместе с тем, для исследования эффективности современных стартапов в традиционной форме недостаточно корректно применять классический инструментарий оценки экономической эффективности компаний и проектов. Так, например, Я. Барбенис и С. Чишти указывают на сложности применения для исследования стартапов классического инструментария оценки эффективности инвестиционных проектов, основанного на процедуре дисконтирования, таких как, в частности, анализ NPV или IRR [1, с. 78]. Сходной точки зрения по данному вопросу придерживается и М.О. Иншаков [3, с. 59]. Е.М. Рогова указывает на ограниченность возможностей применения для исследования эффективности стартапов классических методов финансового анализа [5, с. 171].

Достаточно часто в современной практике исследования эффективности стартапов используется инструментарий скорингового оценивания. Скоринг в наиболее общем виде представляет собой метод достаточно оперативной и укрупненной оценки эффективности функционирования и развития того или иного экономического объекта, в том числе стартапа. Методики скорингового оценивания предлагают, в частности, такие исследователи рассматриваемой нами проблемы, как С. Бланк [2, с. 111], Э. Кесслер [4, с. 53], И.А. Самсонов [6, с. 67] и др. В 
целом, скоринговые методики исследования эффективности стартапов продолжают и развивают инструментарий классического экспертного оценивания финансово-экономических объектов.

По нашему мнению, метод скорингового оценивания эффективности стартапов имеет следующие основные недостатки:

- недостаточная обоснованность показателей скоринговой оценки эффективности стартапа;

- акцентирование внимания, как правило, только на конъюнктурной эффективности стартапа, без учета параметров его возможной долгосрочной, пролонгированной эффективности (после трансформации успешного стартапа в масштабный инновационный проект);

- не уделяется внимание оценке степени сбалансированности отдельных параметров скоринговой оценки стартапа.

Для устранения указанных недостатков традиционной методики скоринговой оценки нами предлагается усовершенствованная методика скоринговой оценки стартапов сферы услуг, которая включает в себя следующие этапы:

1. Обоснование показателей как текущей, так и перспективной (долгосрочной) оценки эффективности стартапа.

2. Осуществление экспертной оценки сравнительной значимости показателей каждой группы для стартапов определенной отрасли сферы услуг по шкале от 0 до 1 с тем, чтобы суммарный вес значимости показателей составил единицу. Такого рода оценка может быть осуществлена посредством инструментария экспертного анализа.

3. Определение степени эффективности составных элементов по каждому стартапу по шкале от 0 до 10 баллов для каждого параметра оценки.

4. Расчет средней взвешенной оценки эффективности каждого из стартапов как в конъюнктурном, так и в долгосрочном периоде.

5. Оценка степени согласованности отдельных параметров развития стартапа на основании расчета средних квадратических оценок экспертных баллов.

В соответствии с усовершенствованной методикой скоринговой оценки, нами предлагаются следующие основные показатели оценки эффективности стартапов, дифференцированные в рамках конъюнктурного и долгосрочного периодов (таблица 1).

При этом для показателей предлагаемой методики усовершенствованной скоринговой оценки эффективности стартапов сферы услуг, представленных в таблице 1 , характерны следующие закономерности:

$$
\begin{aligned}
& a{ }^{*} \mathrm{bi}=\mathrm{ci} \\
& \mathrm{xi}{ }^{*} \mathrm{yi}=\mathrm{zi} \\
& \mathrm{K}=\sum \mathrm{ci} \\
& \mathrm{D}=\sum \mathrm{zi}
\end{aligned}
$$

где ai - экспертная оценка значимости i-го показателя для конъюнктурной оценки эффективности стартапов данной сферы (отрасли сектора услуг в целом);

bi - оценка фактической эффективности i-го параметра для конкретного стартапа в конъюнктурном (краткосрочном) периоде;

сі - итоговый балл оценки і-го параметра

\begin{tabular}{|c|c|c|c|c|c|c|c|}
\hline \multicolumn{4}{|c|}{ Коньюнктурная оценка стартапа } & \multicolumn{4}{|c|}{ Долгосрочная оценка стартапа } \\
\hline Показатели & $\begin{array}{l}\text { Значи- } \\
\text { мость }\end{array}$ & Балл & Итого & Показатели & $\begin{array}{l}\text { Значи- } \\
\text { мость }\end{array}$ & Балл & Итого \\
\hline 1. Оригинальность & a1 & $\mathrm{b} 1$ & c1 & 1. Инновационность & $\mathrm{x} 1$ & $\mathrm{y} 1$ & $\mathrm{z} 1$ \\
\hline $\begin{array}{l}\text { 2. Наличие платежеспо- } \\
\text { собного спроса } \\
\end{array}$ & $\mathrm{a} 2$ & b2 & c2 & $\begin{array}{l}\text { 2. Устойчивость спроса } \\
\text { в долг. периоде }\end{array}$ & $\mathrm{x} 2$ & y2 & z2 \\
\hline $\begin{array}{l}\text { 3. Качество команды } \\
\text { стартапа }\end{array}$ & a3 & b3 & c3 & $\begin{array}{l}\text { 3. Человеческий капи- } \\
\text { тал развития стартапа }\end{array}$ & x3 & y3 & z3 \\
\hline $\begin{array}{l}\text { 4. Доступность кратко- } \\
\text { срочного финансиро- } \\
\text { вания }\end{array}$ & $\mathrm{a} 4$ & b4 & c4 & $\begin{array}{l}\text { 4. Доступность долго- } \\
\text { срочного финансиро- } \\
\text { вания }\end{array}$ & $\mathrm{x} 4$ & y4 & $\mathrm{z} 4$ \\
\hline $\begin{array}{l}\text { 5. Конъюнктурные воз- } \\
\text { можности интеграции }\end{array}$ & a5 & b5 & c5 & $\begin{array}{l}\text { 5. Перспективные воз- } \\
\text { можности интеграции }\end{array}$ & $\mathrm{x} 5$ & y5 & z5 \\
\hline Всего & 1,0 & $\mathrm{x}$ & $\mathrm{K}$ & Всего & 1,0 & $\mathrm{x}$ & $\mathrm{D}$ \\
\hline
\end{tabular}
конъюнктурной эффективности стартапа;

$\mathrm{xi}$ - экспертная оценка значимости i-го по-

Таблица 1. Предлагаемая система показателей оценки эффективности стартапов сферы услуг 
казателя для долгосрочной оценки эффективности стартапов данной сферы (отрасли сектора услуг в целом);

уі - оценка фактической эффективности і-го параметра для конкретного стартапа в конъюнктурном (краткосрочном) периоде;

zi - итоговый балл оценки і-го параметра конъюнктурной эффективности стартапа;

$\mathrm{K}$ - суммарная скоринговая оценка эффективности стартапа в конъюнктурном периоде $($ Кмах $=10$ баллов $)$;

D - суммарная скоринговая оценка эффективности стартапа в долгосрочном периоде $($ Dmax $=10)$.

Соответственно, в рамках усовершенствованной нами методики скоринговой оценки, наиболее эффективным будет стартап сферы услуг, удовлетворяющий системе следующих условий:

$$
\left\{\begin{array}{l}
\mathrm{K} \rightarrow \max \\
\mathrm{D} \rightarrow \max \\
\delta(\mathrm{b}) * \delta(\mathrm{y}) \rightarrow \min
\end{array}\right.
$$

где $\delta(b), \delta$ (у) - средние квадратические отклонения баллов по конъюнктурной и долгосрочной оценке эффективности стартапа, соот- ветственно.

Тем самым, в соответствии с инструментарием усовершенствованной нами методики скоринговой оценки эффективности, наиболее потенциально предпочтительными являются те стартапы, которые характеризуются одновременно высокой конъюнктурной и долгосрочной эффективностью, а также имеют сбалансированные, существенным образом не различающиеся, балльные оценки отдельных параметров стартапа.

В целом, основными отличиями усовершенствованной нами методики по сравнению с традиционным скоринговым анализом стартапов являются:

- учет в единой системе координат не только конъюнктурной, но и возможной долгосрочной эффективности стартапа;

- разносторонний учет параметров стартапа (инновационность, интегративность, качество кадрового, финансового обеспечения и т.п.);

- оценка степени сбалансированности отдельных параметров стартапа посредством расчета среднего квадратического отклонения баллов.

\section{Библиографический список}

1. Барбенис Я., Чишти С. Финтех. Путеводитель по новейшим финансовым технологиям.- М.: Альбина паблишер, 2017.- 676 с.

2. Бланк С. Стартап: настольная книга пользователя.-М.: Альбина Паблишер, 2017.-284 с.

3. Иншаков М.О. Инновационные стартапы в России.- М.: Пресса, 2018. - 132 с.

4. Кесслер Э. Радикальный стартап. М.: Альбина диджитал, 2018. - 480 с.

5. Рогова Е. М. Венчурный менеджмент / Е. М. Рогова, Е.А. Ткаченко, Э.А. Фияксель; Гос. Ун-т - Высшая школа экономики. М.: Изд. Дом Гос. Ун-та - Высшей школы экономики, 2017. - 380 с.

6. Самсонов И.А. Проблемы финансирования стартапов сферы услуг // Менеджмент в России. - 2018. - № 7.С. 67-71. 